\title{
The Effects of Water Stress and Brassinosteroid on Apple Varieties
}

\author{
Sudarshna Kumari ${ }^{{ }^{*}}$ and Anju Thakur ${ }^{2}$
}

${ }^{1}$ Dept. of Plant physiology, GB Pant University of Agriculture and Technology Pantnagar, Uttrakhand (263 145), India

${ }^{2}$ Dept. of Basic Sciences, Dr. YS Parmar University of Horticulture and Forestry Nauni, Solan, Himachal Pradesh (173 230), India

\section{Corresponding Author}

Sudarshna Kumari

e-mail: sudarshnakumari89@gmail.com

\author{
Article History \\ Article ID: IJEP0278 \\ Received in $31^{\text {st }}$ December, 2018 \\ Received in revised form $08^{\text {th }}$ January, 2019 \\ Accepted in final form $21^{\text {st }}$ January, 2019
}

\begin{abstract}
In Himachal Pradesh-India, Apple is mainly grown under rainfed conditions. Moreover, the rainfall is not well distributed throughout the year. Most of the rainfall is received during the monsoon and winter seasons and there is very less or no rains during critical periods of growth and development. Thus, the soil moisture generally remains very low during the summer months and a water stress condition develops. This study was undertaken to identify morphological and physio-biochemical changes in one-year-old young grafted apple seedling plants of two varieties i.e. Super Chief and Red chief (Malus $\times$ domestica Borkh) under 15 and 30 days of induced water stress followed by 0.05 $\mathrm{ppm}$ brassinosteroid and $0.1 \mathrm{ppm}$ brassinosteroid under pot culture study. The brassinosteroid regulates a broad spectrum of plant growth and physio-biochemical processes. One of the most promising roles of brassinosteroid is their ability to confer resistance to a wide array of abiotic stresses. In my study, the maximum reduction in growth and physio-biochemical traits was registered by plants subjected to 30 of water stress as compared to 15 days of water stress than control for both cultivars. However, brassinosteroid at both concentrations could help in maintaining vital growth and physio-biochemical processes under water stress conditions. Foliar spray of brassinosteroid $(0.05$ ppm) prior to imposition of stress can pave the way to minimize the deleterious effects of water stress on apple plants.
\end{abstract}

Keywords: Apple, brassinosteroid, physio-biochemical, plant growth, water stress

\section{Introduction}

Water stress is one of the most adverse factors of plant growth and productivity and considered a severe threat for sustainable crop production in the conditions of changing the climate (Singh et al., 2016). Out of total land under stresses in the world, $26 \%$ is affected by drought (Alizadeh et al., 2011). Drought triggers a wide variety of plant responses, ranging from cellular metabolism to changes in growth rates and crop yields. Understanding the biochemical, physiological and molecular responses to drought is essential for a holistic perception of plant resistance mechanisms to drought-induced changes at morphological, physiological and biochemical levels.

Phytohormones have been implicated in modulating plant response to desiccation stress. Plant growth regulators are involved in the stress response and appear to minimise the impact of stress on growth and to trigger stress resistance mechanism. Plant growth regulator mediated physiological and biochemical changes have been shown to play a vital role during water deficit. Brassinosteroid regulates a broad spectrum of physiological processes including plant growth, vascular differentiation and photomorphogenetic processes.
One of the most promising roles of brassinosteroid is their ability to confer resistance to a wide array of abiotic stresses. Research studies dealing with brassinosteroids revealed that these hormones are able to elicit a broad spectrum of both positive and undesirable physiological and morphological responses in plants, including stem elongation, leaf bending and epinasty, floral initiation, development of flowers and fruits, synthesis of nucleic acids and proteins, regulation of carbohydrate assimilation and allocation and activation of photosynthesis (Bajguz and Hayat, 2009). Several brassinosteroid analogues with a structure similar to the natural brassinosteroids have been shown to be useful in agriculture (Zullo and Adam, 2002).

\section{Materials and Methods}

\subsection{Study site}

The experiment was conducted at an elevation of 1250 $\mathrm{m}$ above mean sea level at $30^{\circ} 51^{\prime} \mathrm{N}$ latitude and $76^{\circ} 11^{\prime} \mathrm{E}$ longitude in the Department of Fruit Science, Dr Yashwant Singh Parmar University of Horticulture and Forestry, Nauni, Solan, Himachal Pradesh. The experimental orchard lies under the sub-temperate, sub-humid mid-hill agro-climatic zone II of 
Himachal Pradesh where, summer is moderately hot during May-June while, winter is quite severe during DecemberJanuary. The annual rainfall ranges between $110-120 \mathrm{~cm}$ and the major amount of which is received from mid-June to September.

\subsection{Treatments and materials}

The suitable methodology has been used to understand the response of apple seedlings to different levels of imposed conditions of water stress alone and in combination with different concentrations of brassinosteroid under controlled conditions. One-year-old seedlings of apple varieties i.e. Super chief and Red chief were planted in plastic pots of $85 \times 30$ $\mathrm{cm}^{2}$ (diameterxheight) and filled with soil and FYM (3:1). Planting was done under natural condition, in the first week of February 2016. Various treatments comprised: $T_{1}$ - Control (No water stress), $T_{2}$ - Water stress for 15 days, $T_{3}$ - Brassinosteroid 0.05 ppm followed by 15 days water stress, $T_{4}$ - Brassinosteroid $0.10 \mathrm{ppm}$ followed by 15 days water stress, $\mathrm{T}_{5}$ - Control (To compare 30 days water stress), $\mathrm{T}_{6}$ - Water stress for 30 days, $\mathrm{T}_{7}$ - Brassinosteroid $0.05 \mathrm{ppm}$ followed by 30 days water stress, $\mathrm{T}_{8}$ - Brassinosteroid $0.10 \mathrm{ppm}$ followed by 30 days of water stress. Water stress conditions were imposed by withholding watering for 15 and 30 days respectively. Before subjecting plants of both varieties to water stress conditions, pots were brought to the field capacity.

\subsection{Observations recorded}

Well-watered control was maintained at nearly field capacity for comparison. The plants were allowed to experience water stress conditions for 15 and 30 days withholding water. Observations regarding growth parameters, viz. plant height, leaf area, root/shoot fresh and dry weight and root: shoot were recorded according to standard procedures and transpiration rate and stomatal conductance with LICOR-6200 portable photosynthesis system during the study. Total free amino acid content in leaves of same age of unstressed and stressed plants was estimated by the method described by Lee and Takahasi, 1996. Proline content was estimated by the method of Singh et al., 1972. The method of Nelson (1944) was adopted for the determination of total soluble sugars. Same procedure for extraction of Catalase enzyme was followed as per the peroxidase Abohatem et al. (2011). Data on plant growth, physiological and biochemical characteristics of apple cultivars to determine the significance of differences were analyzed by using Completely Randomized Design (CRD) with three replications. All data were subjected to tcal $<$ t value carried out using SPSS computer package (SPSS Inc. USA).

\section{Results and Discussion}

\subsection{Plant growth parameters}

Withholding water from planted pots leads to the reduction in plant height and physio-biochemical it is evident from the data presented in Table 1 and 2. The differential response of two varieties of apple i.e. Super chief and Red chief to
Table 1: Effect of water stress and brassinosteroid on apple varieties viz. Super chief and red chief

\begin{tabular}{lccc}
\hline Growth parameter & Super chief & Red chief & \multirow{2}{*}{$\mathrm{t}_{\text {cal }}$} \\
\cline { 2 - 3 } & Mean & Mean & \\
\hline Plant height & 78.87 & 68.73 & 0.14 \\
Number of branches & 2.09 & 1.96 & 0.12 \\
Collar diameter & 7.18 & 7.08 & 0.16 \\
Root length & 73.75 & 63.76 & 0.13 \\
Leaf area & 45.05 & 41.06 & 0.14 \\
Shoot fresh weight & 58.83 & 53.77 & 0.14 \\
Shoot dry weight & 27.97 & 20.07 & 0.08 \\
Root fresh weight & 54.39 & 44.42 & 0.12 \\
Root dry weight & 24.18 & 14.68 & 0.14 \\
Root:shoot Ratio & 0.90 & 0.73 & 0.19 \\
\hline
\end{tabular}

Table 2: Effect of water stress and brassinosteroid on apple varieties viz. super chief and red chief

\begin{tabular}{|c|c|c|c|}
\hline \multirow[t]{2}{*}{ Growth parameter } & Super chief & Red chief & \multirow[t]{2}{*}{$\mathrm{t}_{\mathrm{cal}}$} \\
\hline & Mean & Mean & \\
\hline Photosynthetic rate & 9.22 & 9.09 & 0.26 \\
\hline Chlorophyll fluorescence & 0.71 & 0.68 & 0.18 \\
\hline Transpiration rate & 26.45 & 24.83 & 0.20 \\
\hline Stomatal conductance & 0.69 & 0.67 & 0.15 \\
\hline $\begin{array}{l}\text { Canopy temperature } \\
\text { depression }\end{array}$ & 2.00 & 1.91 & 0.13 \\
\hline Water use efficiency & 0.35 & 0.36 & 0.23 \\
\hline Net assimilation rate & 0.01 & 0.01 & 0.15 \\
\hline Total free proline & 71.20 & 70.64 & 0.13 \\
\hline Total free amino acids & 6.63 & 6.91 & 0.08 \\
\hline Soluble sugars & 43.22 & 42.49 & 0.08 \\
\hline Catalase activity & 0.72 & 0.71 & 0.07 \\
\hline Peroxidase activity & 0.32 & 0.32 & 0.04 \\
\hline $\begin{array}{l}\text { Drought tolerance } \\
\text { efficiency }\end{array}$ & 89.02 & 81.57 & 0.22 \\
\hline Soil moisture content & 16.19 & 16.17 & 0.30 \\
\hline
\end{tabular}

water stress and brassinosteroids is given in Table 1 t-test indicates that tcal < t table value at 60 i.e. 2.60. Therefore, it is evident that all the treatments exhibited the same effect on both varieties i.e. Super chief and Red chief for all the growth indices i.e. Plant height, number of branches, collar diameter, root length, leaf area, shoot fresh weight, shoot dry weight, root fresh weight, root dry weight and root-shoot ratio.

\subsection{Physio-chemicals parameters}

The differential response of two varieties of apple i.e. Super chief and Red chief to water stress and brassinosteroids is 
given in Table 2. T-Test indicates $\mathrm{tcal}<\mathrm{t}$ table value i.e. 2.60 at 60. Therefore, it is evident that all the treatments exhibited the same effect on both varieties i.e. Super chief and Red chief for all the physio-biochemical parameters i.e. Photosynthesis, chlorophyll fluorescence, canopy temperature depression, transpiration rate, stomatal conductance, water use efficiency, net assimilation rate, total free amino acid, total free proline, total soluble sugars, peroxidase and catalase. The treatments have also the similar effect on drought tolerance efficiency and soil moisture content in both varieties i.e. Super chief and Red chief respectively.

During the course of the present investigation the physiobiochemical parameters i.e. photosynthetic rate, chlorophyll fluorescence, canopy temperature depression, stomatal conductance, transpiration rate and water use efficiency were significantly influenced both by treatments as well as durations in one-year-old plants of both varieties viz. Super chief and Red chief. Our studies revealed that in both varieties, maximum photosynthesis and chlorophyll fluorescence were recorded in control i.e. unstressed plants, whereas minimum was observed in stress alone (Table 1-2). Sharma (1998) reported similar findings in apple and almond, respectively. Water stress suppresses the photosynthesis by reducing the leaf area, closing the stomata and checking the activity of dehydrated protoplasmic machinery (Taiz and Zeiger, 1998). Alleweldt and Ruhl (1982) also reported 33 to $48 \%$ reduction in photosynthetic rate in plants grown under water stress conditions. Boyer (1976) noted that photosynthesis was partially or completely inhibited by water stress, but prolonged water deficits resulted in photosynthetic acclimation to water stress. Our finding indicated a parallel decline in photosynthesis and stomatal conductance. The linear correlation between photosynthesis and stomatal conductance in apple trees under water stress might be responsible for the reduction in leaf area and photosynthetic rate (Davies and Lakso, 1979). Water limitation has numerous effects on photosynthesis that have been reported extensively. The initial effect of water limitation on photosynthesis is usually due to stomatal closure, which may close because of root signal because of low turgor pressure in guard cells. Non-stomatal inhibition of photosynthesis during water stress normally accounts for a larger proportion of photosynthetic inhibition as water potential becomes lower. All these inhibitions may occur concurrently (Osmond and Grace, 1995). Our studies indicated that brassinosteroid at both concentrations was found beneficial in contracting the deleterious effects of water stress on physiological parameters. This is in concurrence with the findings of Yuan et al. (2010) who reported that stomatal conductance and net photosynthetic rate of tomato seedlings were significantly decreased by water stress, whereas 24-epibrassinosteroid application significantly increased photosynthetic rate while it decreased stomatal conductance after water cessation.

During the course of present investigations, water stress led to the reduction in chlorophyll fluorescence ( $\mathrm{Fv} / \mathrm{Fm}$ ) which indicates the quantum efficiency of PS-II. It is well established that PS II plays a key role in photosynthetic response to drought and unfavourable environmental conditions (Misra et al., 2012). Balaguer et al. (2002) also reported reduced chlorophyll fluorescence of PS II (Fv/Fm) in Banana under water stress conditions. Light harvesting and electron transport associated with photosystem-II is preferentially decreased as compared to that of photo system-I by water stress. Fluorescence by the light harvesting pigments of plants is one of the main pathways for the deactivation of photosystem II (responsible for over 95\% of chlorophyll fluorescence). The amount of fluorescence is a complicated function of light captured by chlorophyll and the rate of electron flow of PS II. It is noteworthy that pretreatment of brassinosteroid ( 0.05 and $0.10 \mathrm{ppm}$ ) at both the concentration before the imposition of water stress could help in maintaining higher photosynthetic rate and chlorophyll fluorescence than that observed in stressed plants.

Water stress for 15 and 30 days led to the reduction in canopy temperature depression with a higher reduction in 30 days stressed plants. Pretreatment with brassinosteroid both at 0.05 and $0.10 \mathrm{ppm}$ concentrations before imposing water stress resulted in reversing the effects of water stress by maintaining higher values of CTD as compared to stress. Thus, brassinosteroid was found beneficial in minimizing the deleterious effects of water stress on apple varieties i.e. Super chief and Red chief. In general, CTD has been used to assess plant water relationship because it represents an overall, integrated physiological response to drought and high temperature. CTD is affected generally by biological and environmental factors like water status of soil, wind, evapotranspiration, cloudiness, plant metabolism, air temperature and relative humidity (Reynolds et al., 2001). Higher CTD is a desirable parameter since it reflects the cooler canopies, which help in maintaining the proper balance between anabolic and catabolic processes and in minimizing the deleterious effects of water stress. Therefore, the canopy temperature depression also reflects the need for irrigation. Higher canopy temperature lower CTD is common in waterstressed plants (Helyes et al., 2006).

Transpiration rate and stomatal conductance decreased with the decrease in soil moisture content in both the varieties. The reduced transpiration rate might be due to depletion in the available soil moisture content under water stress conditions, which signals for the accumulation of abscisic acidlike substances in the leaves, which may ultimately cause the reduction in stomatal pore size and reduced transpiration rate. Bhardwaj (2010), who observed varying stomatal conductance in apple plant under different soil moisture regimes, have reported similar findings. The higher transpiration rates at -0.5 bar level of irrigation were attributed to the fact that under more frequent irrigations, the stomatal pore size increases (Misger and Kumar, 2008). Chandel and Chauhan (1990) have 
also observed higher transpiration rate and lower stomatal resistance under frequent irrigation in apple. The lowest transpiration at -10.0 bar irrigation treatment might be due to the adaptive protective mechanism against moisture stress operative in the plants. At reduced availability of soil moisture, the resulting tendency of leaf for avoiding dehydration is to cause stomatal closure which further leads to the reduction in transpiration (Nath, 1993).

These studies revealed that total free proline, total free amino acids, soluble sugars, accumulated substantially at the advent of water stress in both the varieties i.e. Super chief and Red chief. In variety Super chief and Red chief maximum proline accumulation i.e. 36.70 and $36.95 \%$ respectively was registered by water-stressed plants. Proline accumulation is in agreement with the findings of earlier workers who have observed a significant increase in proline content at the advent of water deficit (Bhardwaj, 2010). Accumulation of proline in plant tissues is a clear marker for environmental stress, particularly in apple plants under drought stress (Yanbao et al., 2006). Proline is mainly a cytoplasmically compatible osmotic substance and highly soluble in water. So, higher accumulation of proline during water stress helps the plants to maintain higher internal water content by affecting osmotic potential ( $\left.\Psi_{\mathrm{s}}\right)$, a component of water potential, thus resulting in better drought adaptability. Proline and total free amino acids are often increased in water-stressed leaves. Proline act as an organic osmoregulator that can improve the drought resistance of plants (Yoshiba et al., 2006). There are several reports of an increase in sugars solution and proline in apple under drought stress. Jie et al. (2010) reported that under drought stress proline at high levels was accumulated in different organs of apple. The role of proline in the adaptation and survival of plants under drought stress was reported by Watanabe et al. (2000). Osmotic adjustment through the accumulation of cellular solutes, such as proline has been suggested as one of the possible means for overcoming the osmotic stress caused by the loss of water (Mccue and Hanson, 1990) in apple plants. High level of proline enables the plants to maintain low water potentially causing the accumulation of compatible osmolytes that allows additional water to be taken up from the environment, thus causing a buffering effect of water deficit within the organism (Mousa and Abdel Aziz, 2008). Underwater stress, proline concentration can reach up to $80 \%$ of the total amino acid pool. The biochemical defence system against abiotic stress involves the amino acid proline (an osmolyte) which acts as cellular protectors largely accumulated in several plant species in response to abiotic stress and scavenge reactive oxygen species (Ashraf and Foolad, 2007). Proline also serves as a sink for energy to regulate redox potentials, a hydroxyl radical scavenger (Sauter and Dietz, 2002), a solute that protects the macromolecules against denaturation as a means for reducing acidity in the cell. In addition, our studies have also indicated substantial increase in soluble sugar content up to $69.34 \%$ over the control as well as total free amino acids content up to $125 \%$ over the control in plants subjected to 30 days of water stress as compared to 15 day stress duration, which can play an important role to overcome the deleterious effects of water stress in varieties Super chief and Red chief. Several investigators have reported the increase in soluble sugars with increasing water stress (Murakeozy et al., 2003). Accumulation of sugars has a direct connection with the physiological process such as photosynthesis, materials transfer and respiration (Pinheiro et al., 2004). Accumulation of free amino acid content in leaves of water deficit plants induced by water stress plays an important role in osmoregulation. Rai et al. (2003) observed that survival and growth of plants in water stress conditions is the result of adaptation processes such as ion transport; compartmentation of an osmotic solute; synthesis and their accumulation, which leads to the osmotic adjustment and protein, turn over for cellular repair. The increased accumulation of amino acid content is valued in response to osmotic stress since the early accumulation of free amino acid content can contribute to a greater level of stress tolerance. Soluble sugars may function as a typical osmoprotectant, stabilizing cellular membranes and maintaining turgor pressure. Therefore, soluble sugars have been specified as potential osmoregulators since, elevated sugar levels relative to control in stressed plants may contribute to the turgor maintenance (Raggi, 1994).

Brassinosteroids resulted in the enhanced accumulation of osmolytes i.e. sugars, amino acids and proline. Osmolytes play a significant protective role in plant responses to water stress and resistance. Farooq et al. (2009) also observed that the application of BRs increased the free proline levels in rice under drought stress. The findings of the present investigation suggest that BRs are playing a positive role in combating water stress by enhancing the levels of osmoprotectants, metabolites and the activities of enzymes in both cultivars. Our studies revealed that activity of enzymes i.e. catalase and peroxidase were significantly influenced both by treatments and durations in both the varieties i.e. Super chief and Red chief. Maximum catalase and peroxidase activities were observed for 30 days of stress which was followed by pretreatment with brassinosteroid 0.05 and $0.10 \mathrm{ppm}$ before imposing water stress than control i.e. unstressed plants. The findings are in conformity with those of Anuradha and Rao (2001) who observed that exogenous application of brassinosteroid resulted in enhanced tolerance to abiotic stresses in rice. The mitigation of water stress by brassinosteroid was associated with increased scavenging activity and removal of reactive oxygen species as reflected by elevated activities of antioxidant enzymes, catalase and peroxidase. In general, oxidative stress can cause the eventual death of plants due to excessive $\mathrm{H}_{2} \mathrm{O}_{2}$ accumulation. Since stress factors provoke enhanced production of $\mathrm{H}_{2} \mathrm{O}_{2}$ metabolizing enzymes such as superoxide dismutase, catalase, ascorbate peroxidase, peroxidase and glutathione 
sulfotransferases (Sofo et al., 2015). Phytotoxicity from water stress is closely related to the production of reactive oxygen species in plants. An imbalance between ROS production and ROS scavenging leads to oxidative burst. ROS can react with lipids, DNA and proteins, and causes membrane damage and enzyme inactivation resulting in inhibition of plant growth (Mittler, 2002). In order to scavenge ROS and to counter oxidative stress, plants evolved an efficient antioxidant defence system. In our studies, increase in activity of peroxidase and catalase enzyme in stressed plants pretreated with brassinosteroid seems to cope with the harmful effects of water stress. However, it is observed that pants pre-treated with brassinosteroid 0.05 and 0.10 ppm could maintain the significantly higher activity of peroxidase and catalase in stressed plants. These findings are in conformity with those of Bajguz and Hayat (2009) who reported that BRs could regulate antioxidant enzymes such as catalase etc. in plants under different stress conditions. Fariduddin et al. (2009) also showed that 28- homobrassinoloid treatment could elevate antioxidant system including the peroxidase, catalase etc. in Brassica juncea.

\section{Conclusion}

Water stress for 15 and 30 days led to reduction in growth characteristics with higher reduction in 30 days stressed plants. Pre-treatment with brassinosteroid both at 0.05 and 0.10 ppm concentration prior to imposing water stress helped in minimizing the deleterious effects of water stress on apple varieties i.e. Super chief and Red chief both, however 0.05 ppm was more effective in counteracting the effect of water stress.

\section{Acknowledgement}

Authors are highly thankful to the facilities and funds provided by Dr. Yashwant Singh Parmar University of Horticulture and Forestry, Nauni, Solan 173230 (H.P.) India.

\section{References}

Abohatem, M., Zouine, J., Harami, I.E., 2011. Low concentration of BAP and high rate of subcultures improve the establishment and multiplication of somatic embryos in date palm suspension cultures by limiting oxidative browning association with high levels of totalphenols and peroxidase activities. Scientia Horticulturae 130, 344-348.

Alizadeh, A., Alizade, V., Nassery, L., Eivazi, A., 2011. Effect of drought stress on apple dwarf rootstocks. Technical Journal of Engineering and Applied Sciences 3, 86-94.

Alleweldt, C., Ruhl, E., 1982. Untersuchungen Zum Gaswechsel der Rebe. Vitis. Acta Horticulturae 171, 305-314.

Anuradha, S., Rao, S.S.R., 2001. Application of brassinosteroids to rice seeds (Oryza sativa) reduced the impact of salt stress on growth, prevented photosynthetic pigment loss and increased nitrate reductase activity. Plant
Growth Regulators 40, 29-32.

Ashraf, M., Akram, A.N., Arteca, R.N., Foolad, M.R., 2010. The physiological, biochemical and molecular roles of brassinosteroids and salicylic acid in plant processes and salt tolerance. Critical Reviews in Plant Sciences 29, 162-190.

Bajguz, A., Hayat, S., 2009. Effects of brassinosteroids on the plant responses to environmental stresses. Plant Physiology and Biochemistry 47, 1-8.

Balaguer, L., Pugnaire, F.I., Martinez, F.E., Armas, C., Valladares, F., Manrique, E., 2002. Ecophysiological significance of chlorophyll loss and reduced photochemical efficiency under extreme aridity in Stipa tenacissima L. Plant Soil 240, 343-352.

Bhardwaj, K., 2010. Influence of rootstocks and pbr's on growth and physiology of apple under different soil moisture regimes. Thesis. Dr. Y.S. Parmar University of Horticulture \& Forestry, Nauni-173230, Solan (H.P.)

Bhardwaj, R., Arora, N., Sharma, P., Arora, H.K., Thukral A.K., 2010. Stress protective properties of brassinosteroid in plants. Department of Botanical and Environmental Sciences, Guru Nanak Dev University, Amritsar, India. $1-23$.

Boyer, J.S., 1976. Water deficits and photosynthesis. In: Kozlowski T T (editor). Water deficits and plant growth Vol. IV, Acad. Press, New York, 153-190.

Chandel, J.S., Chauhan, J.S., 1990. Effect of rootstocks and soil moisture stress on growth and vigour of apple (Malus domestica Borkh.) cv. Starking Delicious. Punjab Horticultural Journal 30, 162-170.

Davies, F.S., Lakso, A.N., 1979. Water relations in apple. Changes in water potential deficits and plant growth. Acad. Press, New York, 153-190.

Fariduddin, Q., Khripach, S., Hasan, S.A., Ali, B., Hayat, S., Ahmad, A., 2009. Effect of 28-homobrassinolide on the drought stress-induced changes in photosynthesis and antioxidant system of Brassica juncea L. Acta Physiol. Plant 31, 889-897.

Farooq, M., Wahid, A., Basra, S.M.A., Din, I.U., 2009. Improving the water relations and gas exchange with brassinosteroids in rice under drought stress. Journal of Agronomy and Crop Science 195, 262-269.

Helyes, L., Pek, Z., McMichel, B., 2006. Relationship between the stress degree-day index and biomass production and effect and timing of irrigation in snapbean (Phaseolus vulgaris). Acta Botanica Hungarica 48, 3-4.

Jie, Y.Y., John, G., Streeter, Ferree, D.C., 2010. Influence of soil drought stress on photosynthesis, carbohydrates and the nitrogen and phosphorus absorb in different section of leaves and stem of Fugi/M.9EML, a young apple seedling. African Journal of Biotechnology 9, 5320-5325

Lee, Y.P., Takashasi, T., 1966. An improved colorimetric determination of amino acids with the use of Ninhydrin. Analytical Biochem 14, 71-77.

Mccue, K.F., Hanson, A.D., 1990. Drought and salt tolerance: 
Towards understanding and application. Tibtech -December 8, 358-362.

Misger, F.A., Kumar, A., 2008. Effect of soil moisture regimes on plant growth, water relations and yield of Red Delicious/M9 Apple trees. The Horticultural Journal 21, 53-56.

Misra, A.N., Misra, M., Singh, R., 2012. Chlorophyll fluorescence in plant biology. Biophysics. (Ed. Misra, A.N.) ISBN 979953-307-290-5.

Mittler, R., 2002. Oxidative Stress Antioxidants and Stress Tolerance. Trends in Plant Science 7, 405-410.

Mousa, H.R., Abdel-Aziz, S.M., 2008. Comparative response of drought tolerant and drought sensitive maize genotypes to water stress. Australian Journal Crop Sciences 1, 31-36.

Murakeozy, E.P., Nagy, Z., Duhaze, Couchereau, A.Z., 2003. Seasonal changes in the levels of compatible osmolytes in three halophtytic species of inland saline vegetation in Hungary. Journal of plant physiology 160, 395-401.

Nath, R., 1993. Modern Plant Physiology. Kalyani Publishers, New Delhi, 605.

Nelson, N., 1944. A photometric adaptation of the somogyi: method for determination of glucose. Journal of Biological Chemistry 153, 375-380

Osmond, C.B., Grace, S.C., 1995. Perspective on photo inhibition and photo respiration in field: quintessential inefficiencies of light and dark reaction of photosynthesis. J Exp Bot 46, 1351-1362.

Pinheiro, C., Passarinho, J.A., Ricardo, C.P., 2004. Effect of drought and rewatering on the metabolism of Lupinus albus organs. Journal of plant physiology 161, 1203-1210.

Raggi, M.V., 1994. Changes in free amino acids and osmotic adjustment in leaves of water stressed beans. Plant Sciences 167, 427-437.

Rai, S.P., Luthra, R., Kumar, S., 2003. Salt tolerant mutants in glycophytic salinity response (GRS) genes in Catharanthus roseus. Theor. Appl. Genet 106, 221-230.

Sauter, A., Dietz, K.J., Hartung, W., 2002. A possible tress physiological role of abscisic acid conjugates in root-toshoot signaling. Plant Cell Environ 25, 223-228.
Sharma, M.K., 1998. Effect of rootstocks, soil moisture levels and PBR's on growth, physiology and water relations of almond plants. Ph.D. Thesis, Dr YS Parmar University of Horticulture and Forestry, Nauni, Solan.

Singh, T.N., Aspinall, D., Paleg, L.G., Boggess, S.F., 1972. Proline accumulation and varietal adaptation to drought in barley, a potential metabolic measure of drought resistance. Nature New Biology 236, 188-190.

Singh, N., Sharma, D.P., Chand, H., 2016. Impact of climate change on apple production in India: A review. Current World Environment 11, 251-259.

Sofo, A., Scopa, A., Nuzzaci, M., Vitti, A., 2015. Ascorbate peroxidase and catalase activities and their genetic regulation in plants subjected to drought and salinity stresses. International Journal of Molecular Sciences 16, 13561-13578.

Taiz, L., Zeiger, E., 1998. Plant Physiology. Second edition, Sinauer Associates, treatments under the stress of the 1998 drought. Research Circular-ohio-Agricultural University of Horticulture and Forestry, Nauni, Solan.

Watanabe, S., Kojima, K., Ide, Y., Satohiko, S., 2000. Effects of saline and osmotic stress on proline and sugar accumulation in Populus euphratica in vitro. Plant Cell Tiss. Org. 63, 199-206.

Yanbao, L., Chunying, Y., Chunyang, L., 2006. Differences in some morphological, physiological, and biochemical responses to drought stress in two contrasting populations of Populus przewalskii. Physiologia Plantarum 127, 182-191.

Yoshiba, Y., Kiyosue, T., Katagiri, T., Ueda, H., Mizoguchi, T., Yamaguchi, K., Shinozaki, Wada, K., Harada, Y., Yuling, J., Hongqiang, Y., Haizhou, Z., Wei Zhang, D., 2006. Promotion of proline accumulation in apple leaves by bioregulators. Acta Horticulturae, 774.

Yuan, G.F., Jia, C.G., Li, Z., Sun, B., Zhang, L.P., Liu, N., Wang, Q.M., 2010. Effect of brassinosteroid on drought resistance and abscisic acid concentration in tomato under water stress. Scientia Horticulturae 126, 103-108.

Zullo, M.A.T., Adam, G., 2002. Brassinosteroids phytohormones structure bioactivity and applications. Brazil Journal of Plant Physiology 14, 143-181. 